\title{
Pengaruh Model Pembelajaran Reading Questioning And Answering (RQA) Terhadap Hasil Belajar Kognitif Biologi Siswa Kemampuan Akademik Rendah
}

\author{
The Influence Of Reading Questioning And Answering (RQA) Learning Model On \\ Cognitive Learning Result Of Student Low Academic Ability
}

\author{
Siti Ramdiah ${ }^{1 *}$ dan Rabiatul Adawiyah ${ }^{2}$ \\ ${ }^{12}$ Program Studi Pendidikan Biologi STKIP-PGRI Banjarmasin \\ *Koresponden: sitiramdiah@stkipbjm.ac.id
}

\begin{abstract}
Abstrak
Rancangan pembelajaran menjadi bagian penting dalam pelaksanaan proses pembelajaran untuk meningkatkan pemahaman siswa terhadap suatu konsep. Proses pembelajaran yang bermakna jika seluruh siswa baik dengan akademik tinggi maupun rendah dapat memperoleh hasil belajar yang diinginkan oleh tujuan pembelajaran. Dengan demikian guru perlu memanfaatkan model-model pembelajaran dalam melaksanakan hal tersebut. Hal lain yang perlu diperhatikan adalah model pembelajaran yang mampu membantu peningkatan pemahaman siswa akademik rendah. RQA merupakan salah satu model yang diyakini dapat meningkatkan hasil belajar kognitif siswa selama proses pembelajaran. Penelitian ini bertujuan untuk menganalisis pengaruh model pembelajaran reading, questioning and answering terhadap hasil belajar kognitif biologi siswa yang memiliki kemampuan akdemik rendah. Penelitian eksperimen semu ini menggunakan model rancangan yang dikenal dengan "nonequivalent pretest-posttest control group design". Variabel bebas pada penelitian ini yaitu Reading, Questioning, and Answering (RQA) dan variabel terikat yaitu hasil belajar kognitif biologi siswa. Populasi seluruh siswa kelas XI IPA SMA PGRI 6 Banjarmasin. Sampel penelitian ini yaitu siswa kelas XI IPA 1 sebagai kelas eksperimen dengan model RQA dan XI IPA 2 sebagai kelas kontrol dengan pembelajaran konvensional. Teknik pengumpulan data menggunakan tes essay. Data di analisis dengan Anava satu jalur melalui SPSS versi 17 for windows. Hasil analisis penelitian menunjukkan bahwa nilai $\mathrm{F}$ sebesar 30.382 dengan nilai sigifikansi $0.000>0.05$ yang berarti bahwa terdapat pengaruh model RQA terhadap hasil belajar kognitif siswa kemampuan akademik rendah KelasXI IPA SMA PGRI 6 Banjarmasin.
\end{abstract}

Kata kunci : RQA, hasil belajar kognitif, akademik rendah.

\begin{abstract}
The design of learning becomes an important part in the implementation of the learning process to improve students' understanding of a concept. Meaningful learning process if all students either with high or low academics can get the desired learning outcomes by the learning objectives. Thus the teacher needs to utilize the learning models in doing so. Another thing to note is the learning model that can help improve the understanding of low academic students. RQA is one model that is believed to improve students' cognitive learning result during the learning process. This study aims to analyze the influence of learning models of reading, questioning and answering to the cognitive learning result of biology of students who have low academic ability. This quasi-experimental study used a design model known as "nonequivalent pretest-posttest control group design". The independent variables in this study are Reading, Questioning, and Answering (RQA) and the dependent variable is the cognitive learning outcomes of the students biology. Population of all students of class XI IPA SMA PGRI 6 Banjarmasin. The sample of this research is students of class XI IPA 1 as experimental class with RQA model and XI IPA 2 as control class with conventional learning. Technique of collecting data using essay test. Data analysis with Anava one path through SPSS version 17 for windows. The results of the research analysis indicate that the $F$ value of 30.382 with the significance value of $0.000>0.05$ which means that there is an influence of RQA model on the students' cognitive learning result of low academic ability of ClassXI IPA SMA PGRI 6 Banjarmasin.
\end{abstract}

Keywords : cognitive learning result, low academic ability 


\section{PENDAHULUAN}

Proses pembelajaran merupakan salah satu bentuk upaya guru mencapai tujuan pembelajaran yang diinginkan, yaitu dapat meningkatkan pemahaman siswa pada suatu konsep. Menurut Nazliah (2018) proses pembelajaran pada dasarnya merupakan transformasi pengetahuan, sikap dan keterampilan dengan melibatkan aktivitas fisik dan mental siswa. Keterlibatan siswa baik secara fisik maupun mental merupakan bentuk pengalaman belajar siswa yang dapat memperkuat pemahaman siswa terhadap konsep pembelajaran.

Proses pembelajaran tersebut akan berlangsung dengan baik jika sebelumnya pada rancangan telah direncanakan secara sengaja untuk mencapai tujuan pembelajaran. Rancangan yang baik tentunya mempersiapakan proses pembelajaran yang bermakna bagi siswa. Guru dapat merancang proses pembelajaran dengan memanfaatkan berbagai model pembelajaran yang memiliki potensi dalam meningkatkan pemahaman siswa pada suatu konsep. Berdasarkan rancangan tersebut diharapkan siswa mengalami perubahan dalam belajar yang memberi dampak positif terhadap hasil belajar siswa. Dengan demikian maka tujuan dalam sistem pendidikan, baik kurikulum maupun intruksional adalah hasil belajar. Menurut Widodo \& Widayanti (2013) mengemukakan bahwa hasil belajar yang menjadi objek penilaian kelas berupa kemampuan-kemampuan baru yang diperoleh siswa setelah mereka mengikuti proses belajar mengajar. Selanjutnya, jika dicermati bahwa siswa di kelas tidak semuanya memiliki kemampuan akademik yang tinggi, sehingga hal ini perlu diperhatikan lebih seksama agar dalam proses pembelajaran guru tidak hanya membantu sebagian siswa atau hanya memfasilitasi siswa akdemik tinggi saja, namun perlu strategi untuk meningkatakan hasil belajar siswa secara keseluruhan baik akademik tinggi maupun akademik rendah.

Namun, sering dijumpai proses pembelajaran yang tidak demikian, berbagai permasalahan yang berakibat kepada rendahnya hasil belajar siswa. Hal ini diduga karena kurangnya inovasi guru ketika melakukan pembelajaran di kelas, pemilihan strategi atau model-model pembelajaran yang kurang memfasilitasi minat belajar siswa dan berbagai masalah lainnya. Kondisi demikian mengakibatkan rerata hasil belajar yang masih sangat memprihatinkan. Salah satu gambaran dalam suatu proses pembelajaran yaitu lemahnya minat baca siswa untuk memahami konsep lebih mendalam. Proses pembelajaran di dalam kelas diarahkan kepada kemampuan siswa untuk menghafal informasi sehingga siswa dipaksa untuk mengingat dan menimbun berbagai informasi tanpa dituntut untuk memahami 
informasi yang sudah diberikan melalui bahan bacaan. Pelaksanaan pembelajaran yang demikian menyebabkan kemampuan berpikir siswa kurang diberdayakan. Guru dalam mengatasi hal tersebut dapat memilih model pembelajaran yang meningkatkan minat baca dan kemampuan berpikir agar memberikan dampak positif terhadap hasil belajar siswa. Model pembelajaran RQA memiliki tahapan untuk mengatasi hal tersebut. RQA merupakan model pembelajaran yang berlandaskan pada teori pembelajaran konstruktivisme (Bahtiar, 2013). Model ini diharapkan mampu mengubah proses pengajaran yang cenderung tidak relevan dengan pola pendekatan atau model pembelajaran yang digunakan. Dengan demikian, diperlukan upaya untuk melihat efektivitas suatu model pembelajaran agar dapat membantu siswa dalam memahami suatu konsep yang diterimanya. Penelitian ini bertujuan untuk menganalisis pengaruh model pembelajaran reading, questioning and answering terhadap hasil belajar kognitif biologi siswa yang memiliki kemampuan akdemik rendah siswa kelas XI IPA SMA PGRI 6 Banjarmasin.

\section{METODE PENELITIAN}

Jenis penelitian ini menggunakan jenis penelitian eksperimen semu (quasi eksperiment) dengan model rancangan yang dikenal dengan "non equivalent pretets-posttest control group design" Sugiyono (2013). Rancangan penelitian ini digunakan dua kelas subjek. Kelas yang dimaksud yaitu kelas eksperiman dengan pembelajaran menggunakan model RQA dan kelas control dengan pembelajaran konvensional. Tempat penelitian ini dilaksanakan di SMA PGRI 6 Banjarmasin. Populasi dalam penelitian ini adalah seluruh siswa SMA PGRI 6 Banjarmasin kelas XI IPA. Selanjutnya sampel akan diuji kesetaraan berdasarkan nilai Ulangan Tengah Semester (UTS) kelas XI semester 1 mata pelajaran biologi. Selanjutnya, dari kedua kelas sampel ditentukan siswa akademik rendah berdasarkan hasil pretest sebagai pengetahuan awal siswa. Masing-masing kelas berjumlah 18 siswa baik di kelas eksperimen maupun kelas kontrol.

Instrumen pengumpulan data pada penelitian ini yaitu untuk mengukur variabel terikat berupa tes dalam bentuk essay dengan mengacu pada materi pokok system koordinasi Tahun Ajaran 2016/2017. Selanjutnya, digunakan juga rubric penilaian hasil belajar kogntif siswa yang mengacu pada Hart (1994) dengan kisaran 0-4. Prosedur pengumpulan data penelitian melalui kegiatan-kegiatan berikut: 
a. Melakukan pretest pada kelas eksperimen dan kelas kontrol, untuk mengetahui hasil belajar siswa sebelum penerapan model pembelajaran RQA dan pembelajaran konvensional.

b. Pengumpulan data model pembelajaran RQA yaitu mengembangkan dan menyajikan hasil karya pada siswa dalam pembuatan pertanyaan. Setiap kali pertemuan kegiatan akhir proses pembelajaran model RQA, siswa diberikan tugas membaca (reading) materi pelajaran untuk setiap materi, lalu siswa diminta menyusun pertanyaan (questioning). Pertanyaan yang disusun harus mewakili ide pokok dari isi bacaan, kemudian disusun secara tertulis. Bertujuan agar siswa mengevaluasi hasil belajar dan menghasilkan hasil belajar yang baik.

c. Melakukan posttest pada pada kelas eksperimen dan kelas kontrol, untuk mengetahui hasil belajar setelah siswa mengikuti seluruh kegiatan penelitian eksperimen (penerapan model pembelajaran RQA). Pengumpulan data dilakukan dengan teknik tes yang dikerjakan secara individu dalam kelas oleh siswa.

Analisis data dilakukan dengan teknik statistik deskriptif untuk mendeskripsikan data dari variabel penelitian. Pengujian hipotesis dilakukan dengan teknik analisis varian (Anava) satu jalur yang dibantu dengan program SPSS versi 17 for window. Taraf signifikansi yang digunakan dalam pengujian hipotesis adalah $0,05(\mathrm{p} \leq 0,05)$. Sebelum analisis varians (Anava) satu jalur dilakukan dahulu uji asumsi yang meliputi (1) uji normalitas data dan (2) uji homogenitas varian. Taraf signifikansi untuk kedua uji asumsi ini yaitu diterima jika hasil uji menunjukkan nilai diatas 0,05 .

\section{HASIL DAN PEMBAHASAN}

Berdasarkan hasil analisis terhadap uji asumsi untuk uji homogenitas melalui uji Levene's test diperoleh sebesar 0,132 dan uji kolmogorov - smirnov untuk uji normalitas sebesar 0.060, hasil ini menunjukkan bahwa ragam antar kelompok homogeny dan data terdistribusi secara normal. Selanjutnya untuk uji hipotesis hasil analisis menunjukan bahwa nilai $\mathrm{F}$ sebesar 30.382 dengan nilai sigifikansi $0.000>0.05$ dapat dimaknai bahwa model pembelajaran RQA berpengaruh secara signifikan terhadap hasil belajar kognitif siswa berkemampuan akademik rendah. Data lain yang mendukung hasil analisis tersebut sepert inilai rata-rata hasil belajar kognitif siswa juga menunjukkan bahwa dengan penerapan model pembelajaran RQA hasil belajar kognitif biologi siswa akademik rendah lebih tinggi $8.02 \%$ 
dari pada siswa kemampuan akademik rendah dengan pembelajaran konvensional. Paparan data secara ringkas hasil analisis dapat di lihat pada Tabel 1 dan 2.

Tabel 1. Ringkasan anava hasil belajar kognitif biologi siswa

\begin{tabular}{lrrrrr}
\hline & Sum of Squares & df & Mean Square & F & Sig. \\
\hline Between Groups & 367.361 & 1 & 367.361 & 30.382 & 0.000 \\
Within Groups & 411.111 & 34 & 12.092 & & \\
Total & 778.472 & 35 & & & \\
\hline
\end{tabular}

Tabel 2. Hasil perbandingan rata-rata peningkatan hasil belajar kognitif biologi siswa

\begin{tabular}{lccc}
\hline \multirow{2}{*}{ Model Pembelajaran } & \multicolumn{2}{c}{ Rata-rata } & \multirow{2}{*}{ Peningkatan } \\
\cline { 2 - 3 } & Pretest & Postest & \\
\hline RQA & 32.36 & 79.72 & 47.36 \\
Konvensional & 30.25 & 73.33 & 43.08 \\
\hline
\end{tabular}

Berdasarkan data temuan ini dapat dikatakan bahwa model pembelajaran RQA memiliki potensi lebih baik dibandingkan melalui pembelajaran konvensional dalam meningkatkan hasil belajar kognitif biologi siswa. Hasil temuan ini juga sejalan dengan temuan Haerullah dan Usman (2013), Iqbal dan Hariyadi (2015), Akmaliya dan Hapsari (2016), Syarifah, dkk (2016), Bahri (2016), Safitri (2016), Hariyadi, dkk. (2017). Menurut Corebima yang dijelaskan oleh Akmaliya dan Hapsari (2016) bahwa implementasi RQA dapat terlaksana dan pemahaman terhadap materi pembelajaran berhasil ditingkatkan hampir $100 \%$.

Hal tersebut diyakini karena model pembelajaran dengan RQA mampu mempasilitasi proses memahami konsep dengan baik. Jika di analisis secara mendalam tahapan RQA memberikan kontribusi kepada siswa untuk memahami dengan baik, dimana pada tahap pertama yaitu reading, siswa diinformasikan untuk membaca materi yang diberikan. Pada tahap ini siswa dilatih untuk menemukan ide-ide utama dari materi tersebut. Selanjutnya tahap kedua yaitu questioning siswa dilatih untuk mampu membuat pertanyaan dari konsep yang diberikan, kegiatan tahapan ini menuntut siswa untuk dapat mengemukakan pertanyaanpertanyaan berdasarkan ide-ide utama tersebut pada tahap pertama. Tahap berikutnya answering, siswa diberi kesempatan untuk mencari jawaban atas pertanyaan tersebut serta membuat kesimpulan dengan kembali membaca lebih seksama dan cermat agar diperoleh jawaban yang benar. Tahapan ini diyakini dapat melatihkan siswa untuk memproses 
informasi dari materi dengan baik hingga dapat menyimpulkan dengan jelas. Berdasarkan hal tersebut dapat dikatakan bahwa siswa mengalami pengulangan dalam memproses informasi tersebut kondisi ini yang diyakini dapat meningkatkan pemahaman siswa karena materi yang diberikan dapat tersimpan dengan baik di memori jangka panjang (long term memory). Ditambahkan Mulyadi (2014) bahwa model RQA mendorong mahasiswa untuk memahami isi bacaan yang selanjutnya berupaya mencari bagian yang substansial untuk menyusun pertanyaan serta menjawabnya. Kemampuan menyusun pertanyaan dari materi yang dibaca dapat digunakan untuk menilai kemampuan berpikir. Menurut Darmayanti (2015), dalam penerapan pembelajaran RQA terjadi proses asimilasi dan akomodasi. Asimilasi merupakan proses menggunakan struktur atau pengetahuan yang telah dimiliki sebelumnya untuk menghadapi masalah dalam lingkungan. Asimilasi ini terjadi ketika siswa selesai melakukan aktivitas membaca. Proses asimilasi dapat berupa kegiatan menyamakan konsep. Selanjutnya proses akomodasi, dimana siswa memerlukan modifikasi atau perubahan struktur mental yang ada dalam mengadakan respon terhadap tantangan lingkungannya. Tahap akomodasi ini terjadi pada penyusunan dan membuat pertanyaan serta saat siswa membacakan pertanyaan dan jawaban. Dengan demikian dapat dikatakan bahwa model pembelajaran RQA memberikan pengalaman belajar yang bermakna dan memberikan dampak positif terhadap hasil belajar kognitif siswa. Hal ini sesuai dengan pendapat Pinem, dkk. (2015) bahwa dalam proses pembelajaran guru harus mendorong siswa untuk aktif belajar dan memberikan pengalaman belajar yang memadai dengan menggunakan metode - metode pembelajaran yang sesuai dengan materi yang diajarkan.

\section{KESIMPULAN}

Berdasarkan analisis data dan pembahasan tersebut dapat disimpulkan bahwa model pembelajaran RQA berpengaruh terhadap hasil belajar kognitif biologi siswa kemampuan akademik rendah kelas XI IPA SMA PGRI 6 Banjarmasin.

\section{REFERENSI}

Akmaliya, N.I., dan Hapsari, A.I. 2016. Model Pembelajaran Reading, Questioning and Answering (RQA) untuk Meningkatkan Hasil Belajar Siswa. Jurnal BIOMA : Biologi dan Pembelajaran, Vol. 1. No1. 69-80.

http://jurnal.unmuhjember.ac.id/index.php/BIOMA/article/view/154/92 
Bahri, A. 2016. Strategi Pembelajaran Reading Questioning And Answering (RQA) Pada Perkuliahan Fisiologi Hewan Untuk Meningkatkan Hasil Belajar Kognitif Mahasiswa. Jurnal Bionature, Volume 17, Nomor 2, Oktober 2016, hlm. 106-113.

Bahtiar. 2013. Potensi Pembelajaran yang Memadukan Strategi Think Pairs Share (TPS) dan Reading Questioning anf Answering (RQA) untuk Meningkatkan Sikap Sosial dan Penguasaan Konsep Biologi Siswa SMA Multietnis di Ternate. Seminar Nasional X Pendidikan Biologi FKIP UNS, 1-7

Darmayanti, V. 2015. Profil Penguasaan Pembelajaran RQA (Reading, Questioning, and Answering) oleh Guru IPA SMP di Jember. Seminar Nasional Fisika Dan Pembelajarannya FMIPA Universitas Negeri Malang.

Haerullah, A., dan Usman, F.H. 2013. Pengaruh Penerapan Model Reading, Questioning and Answering (RQA) Terhadap Pengetahuan Metakognitif Siswa Kelas XI IPA SMA Negeri

2 Kota Ternate.Jurnal Bioedukasi, Vol. 2 No. $1 . \quad 180-184$ (http://id.portalgaruda.org/?ref=browse\&mod=viewarticle\&article=338543)

Hariyadi, S, Corebima, A.D., Zubaidah, S., Ibrohim. 2017. The Comparison of the Question Types in the RQA (Reading, Questioning, and Answering) Learning Model and Conventional Learning Model. International Journal of Humanities Social Sciences and Education (IJHSSE) Volume 4, Issue 7, July 2017, (Online) http://dx.doi.org/10.20431/2349-0381.0407002 www.arcjournals.org .

Hart, D. 1994. Authentic Assesment A handbook for Education. California, New York: Addision Wesley Publishing Company.

Iqbal, M., dan Hariyadi, S. 2015. Pengaruh Implementasi Strategi RQA (Reading, Questioning, Answering) pada Matakuliah Pengantar Teknologi Informasi dalam Meningkatkan Hasil belajar Mahasiswa.Prosiding Seminar Nasional Pendidikan Sains Tahun 2015 Unesa, http://repository.unej.ac.id/handle/123456789/62634,

Mulyadi, Adlim dan Djufri. 2014. Memberdayakan Kemampuan Berpikir Mahasiswa Melalui Model Pembelajaran Reading QuestioningAnd answering (RQA). Jurnal Biotik, ISSN: 2337-9812, Vol. 2, No. 1, Ed. April 2014, Hal. 1-76.

Nazliah, Rahmi. 2018. Perbandingan Penerapan Strategi Pembelajaran PBL Dan Inquiry Terhadap Hasil Belajar Dan Keterampilan Proses Sains Pada Materi Polusi Lingkungan Di SMA Negeri 1 Kualuh Hulu Aek Kanopan. SIMBIOSA. Vol. 6. No. 2. 111-119.

Pinem, Revida. Sari, P.N., Ramses. 2015. Pengaruh Pendekatan Keterampilan Proses Terhadap Hasil Belajar Biologi Pada Pokok Bahasan Klasifikasi Makhluk Hidup Di Kelas VII SMP Tunas Baru Batam. SIMBIOSA. Vol. 4. No. 2. 105-109.

Safitri, Dewi. 2016. Pengaruh Strategi Reading Questioning and Answering (RQA) dipadukan dengan Think Pair Share (TPS) Terhadap Hasil Belajar Siswa Kelas VIII 
SMP Negeri 2 Colomadu pada Materi Sistem Peredaran Darah Tahun Pelajaran 2015/2016. Publikasi Ilmiah, http://eprints.ums.ac.id/44081.

Sugiyono. 2013. Metode Penelitian Pendidikan (Pendekatan Kuantitatif dan Kualitatif $R$ dan $D)$. Alfabeta, Bandung.

Syarifah, H., Indriwati, S.E., Corebima, A.D. 2015. Pengaruh Strategi Pembelajaran Reading Questioning and Answering (RQA) dipadu Think Pair Share (TPS) Terhadap Keterampilan Metakognitif Siswa Laki-laki dan Perempuan SMAN di Kota Malang. Jurnal Pendidikan: Teori, Penelitian, dan Pengembangan Volume: 1 Nomor: 5 Bulan: Mei Tahun 2016 Halaman: 801-805.

Widodo dan Widayanti, L. 2013. Peningkatan Aktivitas Belajar dan Hasil Belajar Siswa dengan Metode Problem Based Learning pada Siswa Kelas VIIa Mts Negeri Dunomulyo Kulon Progo Tahun Pelajaran 2012/2013. Jurnal Fisika Indonesia XVII (49). 